VOLUME $52 \cdot$ PART $3 \cdot$ DECEMBER 1994

JPLPBZ 52 (Pt 3) 343-485 (1994) 0022-3778
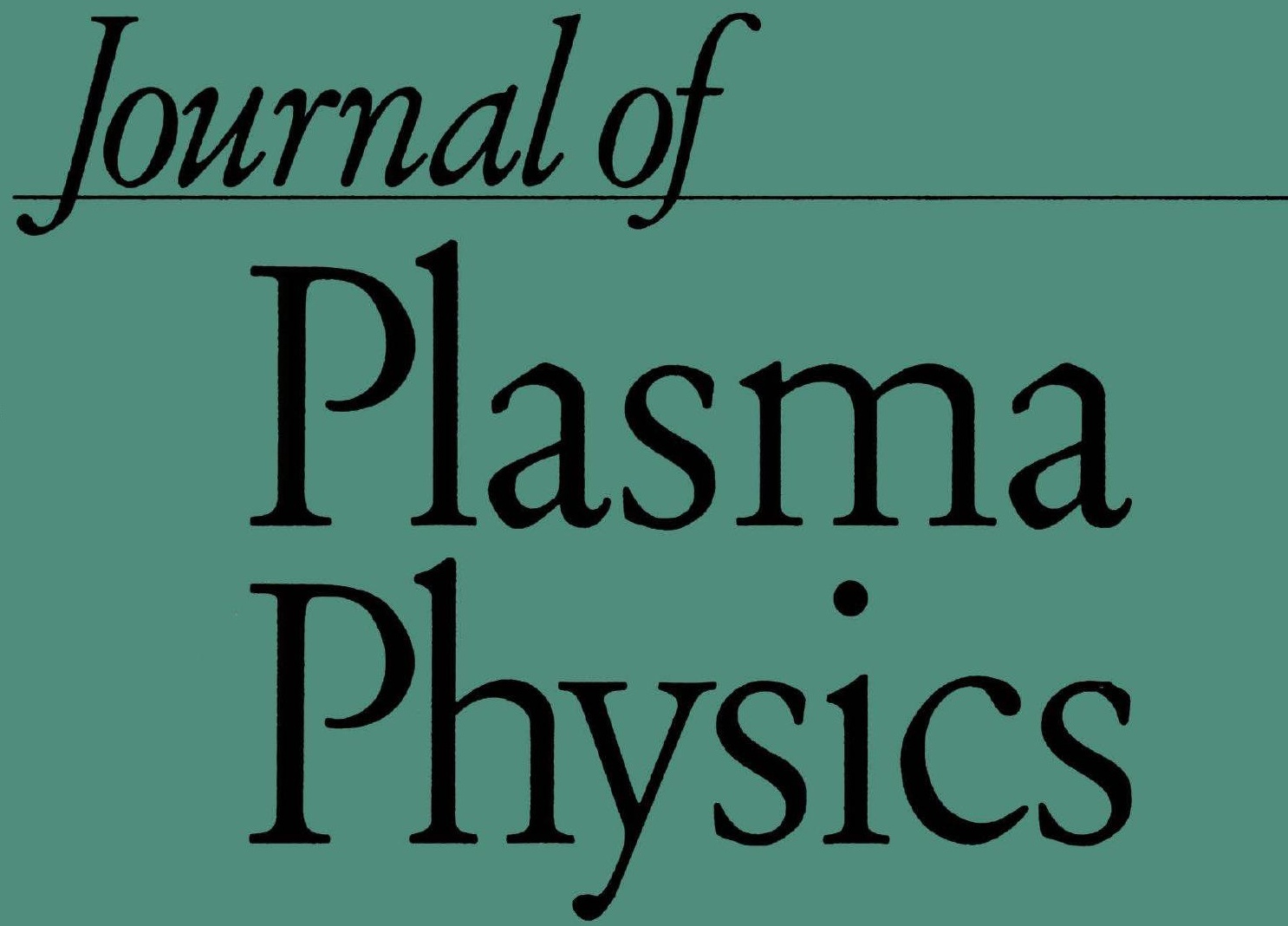
Journal of Plasma Physics exists for the publication of experimental and theoretical research papers on plasma physics and its applications.

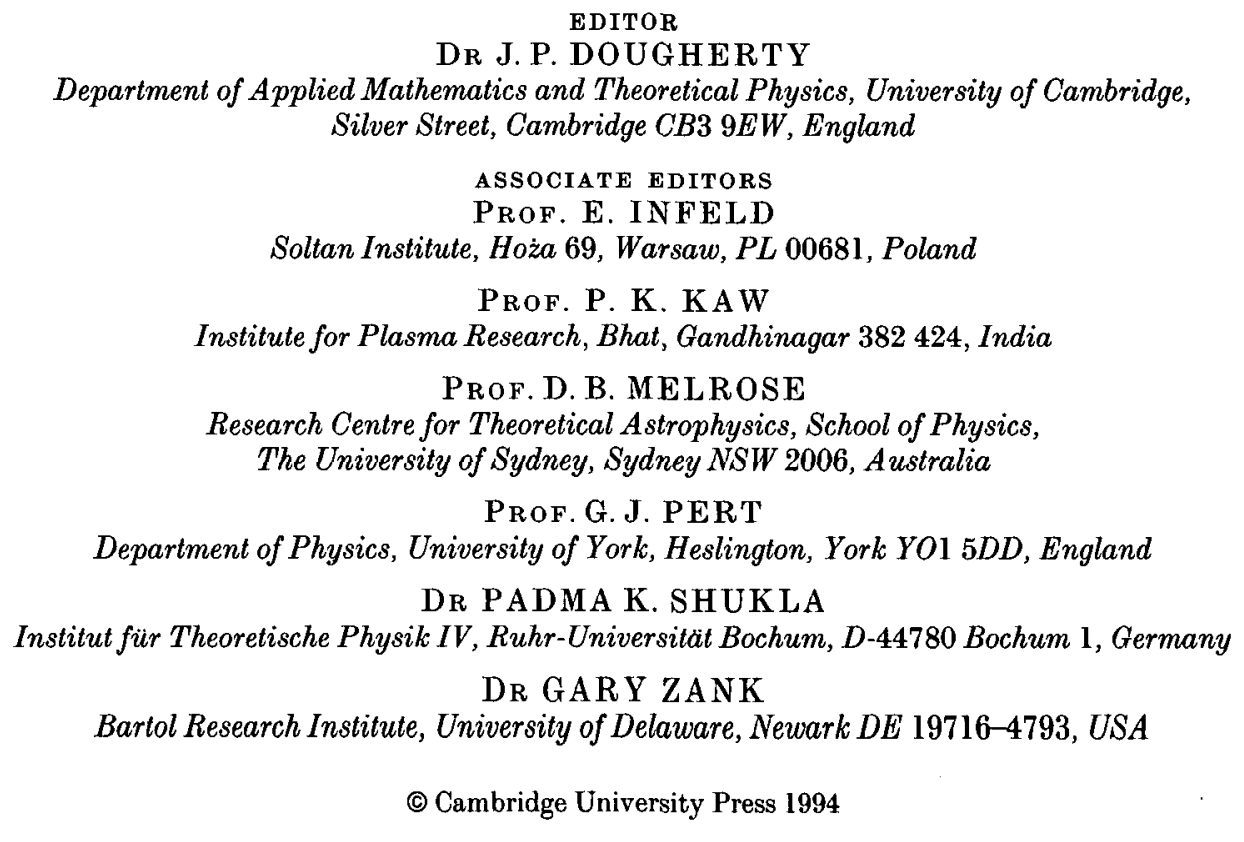

\section{Change of Editor}

With the completion of Volume 52 (1994), Professor R. A. Cairns and Professor George H. Miley will become Editors of the Journal of Plasma Physics. All new submissions should now be sent to:

Professor R. A. Cairns

School of Mathematical and Computational Sciences

University of St. Andrews

KY16 9SS

Fife, Scotland

rac@st-andrews.ac.uk or to Professor George H. Miley

Fusion Studies Laboratory

University of Illinois

103 S Goodwin Avenue

Urbana IL 61801

USA

g-miley@uiuc.edu

or to an appropriate Associate Editor as before.

Journal of Plasma Physics (ISSN 0022-3778) is published once every two months in February, April, June, August, October and December, by Cambridge University Press, The Edinburgh Building, Shaftesbury Road, Cambridge CB2 2RU and Journals Department, 40 West 20th Street, New York, NY 10011-4211.

Three parts form a volume. The subscription price (excluding VAT, but includes postage) of Volumes 51 and 52 (1994) is $\$ 144.50$ net, per volume (US $\$ 275.00$ in the USA, Canada and

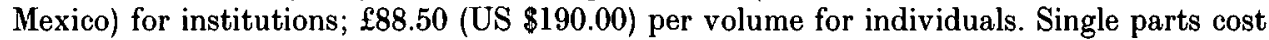
$£ 50.00$ each (US $\$ 95.00$ in the USA, Canada and Mexico) plus postage. All orders must be accompanied by payment.

Copies of the journal for subscribers in the USA, Canada and Mexico are sent by air to New York to arrive with minimum delay.

EC subscribers (outside the UK) who are not registered for VAT should add VA'T at their country's rate. VAT registered subscribers should provide their VAT registration number.

Japanese prices for institutions (including ASP delivery) are available from Kinokuniya Company Ltd, P.O. Box 55, Chitose, Tokyo 156, Japan.

Second class postage paid at New York, NY, and at additional mailing offices. POSTMASTER: send address changes in USA, Canada and Mexico to Journal of Plasma Physics, Cambridge University Press, 110 Midland Avenue, Port Chester, New York, NY $10573-4.930$. 